Plant Tissue Cult. \& Biotech. 27(1): 51-61, 2017 (June)

$\overline{\text { PTC\&B }}$

\title{
Somatic Embryogenesis and Subsequent Plant Regeneration from Zygotic Embryo Derived Callus of Rubber (Hevea brasiliensis Muell. Arg).
}

\author{
Md. Mahbubur Rahman ${ }^{1 *}$, Maziah Mahmood ${ }^{2,3}$, Norhani \\ Abdullah $^{2}$, Noor Azmi Shaharuddin and Waheeda Parvin ${ }^{1,4}$ \\ Department of Biochemistry, Faculty of Biotechnology and Biomolecular Sciences, \\ Universiti Putra Malaysia, 43400, Serdang, Selangor, Malaysia
}

Key words: Hevea brasiliensis, Zygotic embryo, Somatic embryogenesis, Regeneration

\begin{abstract}
A protocol has been developed for induction, maturation and germination of the zygotic embryo derived callus of the rubber tree (Hevea brasiliensis Muell. Arg.). The influence of plant growth regulators (PGRs) including 2,4-D, $\alpha$-NAA, picloram, $\mathrm{GA}_{3}$ and TDZ on MS and MMS were studied. Optimum calli were induced on MS supplemented with $2.0 \mathrm{mg} / 1$ 2, 4-D. The best callus growth and proliferation was recorded on MS fortified with $2.0 \mathrm{mg} / \mathrm{l} 2$, 4-D + $2.0 \mathrm{mg} / \mathrm{l} \mathrm{BAP} \mathrm{+}$ $0.5 \mathrm{mg} / \mathrm{l} \mathrm{NAA}$. The maximum embryonic calli were induced on MS $+2.0 \mathrm{mg} / \mathrm{l} 2$, 4 -D + $2.0 \mathrm{mg} / \mathrm{l} \mathrm{Kn}$ medium. Embryo induction, differentiation and maturation were obtained on MMS (MS +Vit B5). The rooted plantlets were produced on half strength MS without any supplements.The novelty of this study is the induction of embryos and plant regeneration from zygotic embryo explants of Hevea for the first time. The protocol developed in this study will facilitate mass propagation of high yielding rubber clones as well as to develop transgenic rubber plants with desired genes through genetic transformation.
\end{abstract}

\section{Introduction}

The rubber tree (Hevea brasiliensis Muell. Arg.) is an important industrial crop for natural rubber production. At present about 40 countries including Bangladesh are engaged in rubber tree cultivation aimed at producing about 6.5 million tons of dry rubber annually. The world supply of natural rubber is barely keeping up

*Author for correspondence: < mahbub_bfri90@yahoo.com> Bangladesh Forest Research Institute, Chittagong-4000, Bangladesh. 'Institute of Tropical Agriculture, Universiti Putra Malaysia, 43400, Serdang, Selangor, Malaysia. 'Institute of Bio Science, Universiti Putra Malaysia, 43400, Serdang, Selangor, Malaysia. ${ }^{4}$ Faculty of Agriculture, Universiti Putra Malaysia, 43400, Serdang, Selangor, Malaysia. 
keeping up with the global demand for 12 million tons of natural rubber by the year 2020. Therefore enhanced rubber production may play an important role in the economy of rubber producing countries. At present about 25,000 hectare of land is under rubber plantation in Bangladesh, and the annual production is about 7,500 tons against 20,000 tons of the country's total demand of natural rubber (NR). In Malaysia the success of the rubber breeding program can be seen from the multi-folds yield increase from about $500 \mathrm{~kg} / \mathrm{ha} /$ year for unselected seedlings to about 3,000 kg/ha/year derived from the selected clones. The average yield of rubber is about 1.6 tons in India. But in Bangladesh under nontraditional conditions-average yield is about 0.5 ton/ha only. Therefore, the development and expansion of rubber, systematic research is needed to improve the yield.

This perennial tree is strongly outcrossing and monoecious. It is the only species, which has been commercially cultivated for latex biosynthesis (rubber production). Due to the high rubber content and quality, it is the most important commercial source of natural rubber. Rubber tree has very narrow genetic base, non-synchronous flowering, low fruit set, long gestation period and heterozygous nature. As a result the genetic improvement of Hevea has been very slow and time-consuming through conventional breeding. Thus, rubber tree breeding and the dissemination of planting material for plantations are closely linked to propagation methods. The cultivated clones are propagated mostly through grafting which affects the tree growth, latex yield, tree physiology and biochemical characteristics (Sobhana et al. 2001, Huang and Lin 2003). Thus, the plant regeneration through somatic embryogenesis has been reported as an effective vegetative propagation method. In $\mathrm{H}$. brasiliensis, it has been reported that the plant regeneration is via somatic embryogenesis in which several explants such as immature anther, inflorescence and inner integument of seed (Sushamakumari et al. 2000b) have been used. But, the technique is still not sufficiently developed for rubber tree improvement because the formation of a reliable somatic embryo and its conversion rate into plantlets is very low and limited to a few genotypes of Hevea. Besides, many clones showed a very low embryo formation and in some clones the embryo formation is negligible. Thus, the present study was undertaken for developing a reliable plant regeneration system via somatic embryogenesis from zygotic embryo derived callus.. The long term goal of this study is to develop a unique plant regeneration system that could be used in mass propagation as well as genetic modification of $H$. brasiliensis. 


\section{Materials and Methods}

Hevea (Clone RRIM 901) seeds were obtained from the Malaysian Rubber Board, Malaysia. After removing the seed coat, the surface sterilization of endosperm was done for 15 min with 15\% Clorox. There after, one drop of Tween 20 was added which followed by washing with sterile water for 5 - 6 times. The embryos were excised from con the callus induction medium.

MS basal medium with B5 vitamins and different auxins including 2, 4-D, NAA, picloram, and Dicamba combination with cytokinins BAP and $\mathrm{Kn}$ at different concentrations were used for callus induction and growth. The concentrations of auxin varied from $0-5.0 \mathrm{mg} / \mathrm{l}$ and that of cytokinins $0-5.0$ $\mathrm{mg} / \mathrm{l}$. The media $\mathrm{pH}$ was adjusted to 5.8 with $3 \%$ sucrose and $2.75 \mathrm{~g} / \mathrm{l}$ gelrite followed by $20 \mathrm{~min}$ of autoclaving at $121^{\circ} \mathrm{C}$. The growth room condition was maintained at $25 \pm 2{ }^{\circ} \mathrm{C}$ in the darkness. Each culture flask contained $30 \mathrm{ml}$ medium with three embryos. Callus induction frequency was recorded after 4 weeks of culture initiation.

The calli were sub-cultured every 2 weeks to optimize the callus growth and proliferation. MS supplemented with different concentrations of 2, 4-D, BAP and $\mathrm{Kn}$ in presence of NAA was tried. The callus diagonal length, fresh and dry weight/culture, and morphologies were recorded every week in order to optimize the growth and to obtain callus maintenance medium.

The calli ( 3 weeks old) were transferred to the embryo induction medium. The MS was supplemented with $B_{5}$ vitamins, amino acid glutamine $(100 \mathrm{mg} / \mathrm{l})$, $10 \%$ coconut water as organic supplements and $200 \mathrm{mg} / \mathrm{l}$ casein hydrolysate with $5 \%$ sucrose. The phytohormones added was within the range of $0.5-3.0 \mathrm{mg} / \mathrm{l}$ $\mathrm{Kn}, 0$ - $3.0 \mathrm{mg} / \mathrm{l} \mathrm{GA}_{3}, 0.1 \mathrm{mg} / \mathrm{l} \mathrm{NAA}$ and $0.5 \mathrm{mg} / 1$ 2, 4-D. The cultures were kept at $25 \pm 2{ }^{\circ} \mathrm{C}$ in darkness for 4 weeks. Apex induction and maturation of the embryos were examined on the modified MS medium supplemented with phytohormones $\mathrm{BAP}, \mathrm{GA}_{3}$ and TDZ. Plant regeneration from induced embryos was achieved in full or half strength hormone free MS medium. Visual observations were made to record the embryo induction percentage, maturation and germination. Completely randomized design (CRD) was used to carry out the experiments. Data were analyzed using SAS and means were statistically compared using LSD test at $\mathrm{p}<0.05$ significance level.

\section{Results and Discussion}

Hevea plant regeneration through embryogenic cultures was initiated from zygotic embryo explants. The developmental stages of the explants and the type of growth regulators were found to be the most important factors controlling somatic embryogenesis in rubber. 
It was observed that the age of the seeds, developmental stages of embryo, basal medium, types and concentrations of growth regulators influenced the primary callus induction of Hevea zygotic embryo explants. Comparatively mature embryos responded to the cultures quickly. The zygotic embryos collected from immature fruits (less than 80 days after pollination) were not effective to induce primary callus. Hernandez et al. (2003a) made similar observations for somatic embryo induction in Quercus suber. Wilhelm (2000) also reported that the frequency of initiating somatic embryos was associated with the developmental stages of the zygotic embryo explant.

The certain ratio of auxin and cytokinin was important for embryogenic callus induction and maintenance of Hevea. The phytohormones 2,4-D, NAA, $\mathrm{BAP}, \mathrm{Kn}$ and $\mathrm{GA}_{3}$ were found to be ideal for embryogenesis in rubber at different stages. The best callus inducing medium was found in MS supplemented with 2 $\mathrm{mg} / 1$ 2,4-D and 3\% sucrose. 2,4-D and NAA were found more effective than picloram and dicamba. It was observed that the calli started to develop and the induction frequency increased up to 8 weeks of culture. Explants were found to be more prone to callus as well as embryogenic callus induction when the culture media were fortified with $1.0-2.0 \mathrm{mg} / \mathrm{l}$ 2,4-D. All concentrations of 2,4-D, produced callus except the hormone free culture medium. The lowest mean percentage of explants (23.33) induced primary callus after 4 weeks of culture in 2,4-D (2.0 mg/l). This frequency increased up to $90 \%$ after 8 weeks. The following results were observed in different concentrations of NAA, picloram and dicamba successively. The results have been presented in Fig. 1. Khan et al. (2011), obtained similar results in Capsicum annum. A high percentage of embryogenic callus induction could be possible due to auxin and cytokinin which are the main regulators involved in plant cell division and differentiation (Feher et al. 2003).

Different morphologies were observed during the establishment of primary callus lines. The callus induced from $2.0 \mathrm{mg} / \mathrm{l}$ 2,4-D looked yellowish, comparatively fast growing but little friable (Fig. 2a,b) than that of the concentrations of 2,4-D, NAA, picloram and dicamba. Direct organogenesis through profuse roots and shoots were observed in the media with different concentrations of NAA $(2.0-3.0 \mathrm{mg} / \mathrm{l})$ after 2 weeks of subculture from the induced primary callus (Fig. 2c,d). Dicamba and picloram had little response on callus induction when supplied individually with a range of concentration 1.0 $5.0 \mathrm{mg} / \mathrm{l}$. The induced callus was mostly whitish, compact, slow growing and failed to further growth during subculture under the same condition (Fig. 2e, f). 


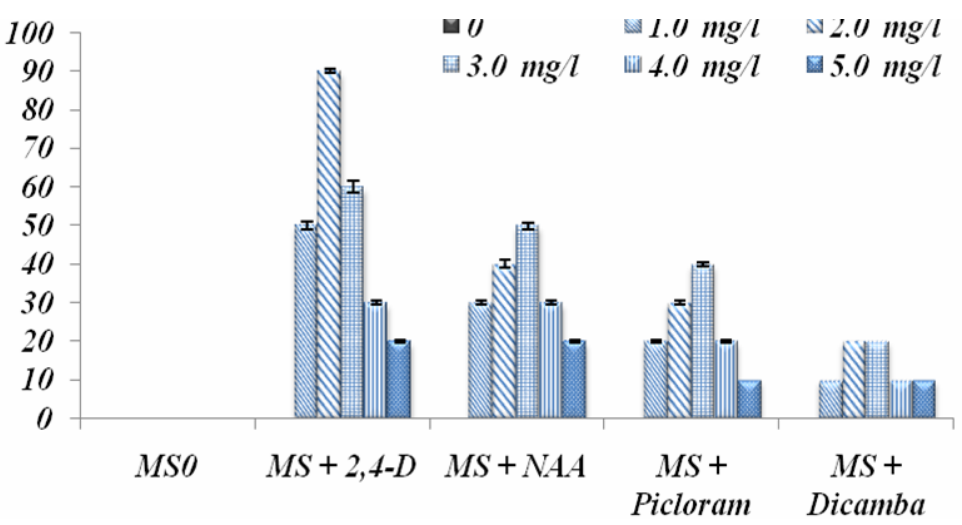

MS + Different auxin concentrations

Fig. 1. The effect of different auxin concentrations on MS on primary callus induction from zygotic embryo of $H$. brasiliensis after 8 weeks of culture. Vertical bars indicated standard errors.

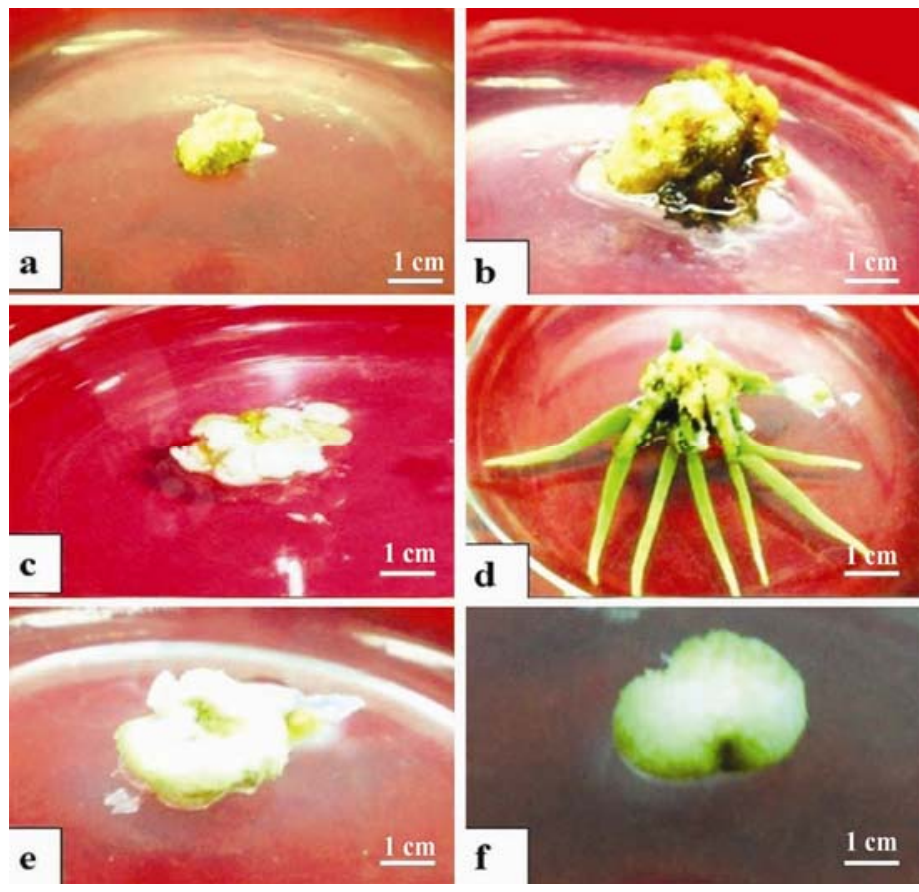

Fig. 2. Morphogenetic response of induced primary callus in MS supplemented with different auxins from zygotic embryo explants of Hevea brasiliensis. a, b. Compact yellowish primary callus induced in MS $+2.0 \mathrm{mg} / \mathrm{l}$ 2, 4-D after 4 weeks of culture and 8 weeks of culture, c. Whitish friable, organogenic callus induced in MS + $2.0 \mathrm{mg} / \mathrm{l}$ NAA after 4 weeks of culture, d. Profuse healthy roots with small shoots observed in MS $+2.0 \mathrm{mg} / 1 \mathrm{NAA}$ after 6 weeks of culture of the induced callus under the same culture condition, e. Whitish compact callus induced in MS +3.0 $\mathrm{mg} / \mathrm{l}$ picloram after 8 weeks of culture, f. Compact dry and whitish callus induced in MS +3.0 $\mathrm{mg} / \mathrm{l}$ dicamba after 8 weeks of culture. 
The results also revealed that the primary callus did not proliferate when it was repeatedly cultured on 2,4-D in the same condition. Therefore, different concentrations of BAP and $\mathrm{Kn}$ were supplemented with 2,4-D concentrations. The supplementation of BAP with 2,4-D at different concentrations was found to be essential for callus proliferation in Hevea.

Different concentrations of BAP and Kn were tried with 2,4-D and NAA to optimize the callus growth and proliferation. The result revealed that $\mathrm{Kn}$ was less effective than BAP for callus growth and proliferation. Besides, the addition of a lower concentration of NAA enhanced the callus growth. The highest mean diagonal length of callus growth $(34.0 \mathrm{~mm})$, fresh weight $(6.18 \mathrm{gm})$ and dry weight $(0.74 \mathrm{gm})$ per culture were recorded in a combination of 2,4-D $(2.0 \mathrm{mg} / \mathrm{l})$ and BAP $(2.0 \mathrm{mg} / \mathrm{l})$ after 3 weeks of culture. The results were presented in Table 1.

Table 1. Influence of 2, 4-D and different concentrations of BAP in presence of $0.5 \mathrm{mg} / 1$ NAA on embryogenic callus growth and proliferation on MS.

\begin{tabular}{|c|c|c|c|c|c|}
\hline \multicolumn{3}{|c|}{$\begin{array}{l}\text { Media compositions } \\
(\mathrm{mg} / \mathrm{l})\end{array}$} & $\begin{array}{l}\text { Diagonal } \\
\text { length }(\mathrm{mm})\end{array}$ & $\begin{array}{l}\text { Fresh weight } \\
\text { of callus (gm) }\end{array}$ & $\begin{array}{l}\text { Dry weight } \\
\text { of callus (gm) }\end{array}$ \\
\hline \multicolumn{3}{|c|}{ MS 0 (Control) } & $0.0 \pm 0.0^{\mathrm{a}}$ & $0.0 \pm 0.0^{\mathrm{a}}$ & $0.0 \pm 0.0^{\mathrm{a}}$ \\
\hline $2,4-\mathrm{D}$ & NAA & BAP & & & \\
\hline \multirow{5}{*}{2.0} & \multirow{5}{*}{0.5} & 1.0 & $27.66 \pm 2.51^{\mathrm{d}}$ & $4.88 \pm 1.91^{\mathrm{bc}}$ & $0.63 \pm 0.28^{c}$ \\
\hline & & 2.0 & $34.00 \pm 1.73^{\mathrm{e}}$ & $6.18 \pm 3.33^{c}$ & $0.74 \pm 0.46^{c}$ \\
\hline & & 3.0 & $25.66 \pm 1.15^{\mathrm{d}}$ & $5.59 \pm 0.00^{c}$ & $0.60 \pm 0.16^{\mathrm{bc}}$ \\
\hline & & 4.0 & $21.00 \pm 1.73^{c}$ & $2.40 \pm 0.47^{\mathrm{ab}}$ & $0.18 \pm 0.06^{\mathrm{ab}}$ \\
\hline & & 5.0 & $16.66 \pm 1.15^{\mathrm{b}}$ & $1.86 \pm 0.02^{\mathrm{b}}$ & $0.16 \pm 0.05^{\mathrm{ab}}$ \\
\hline
\end{tabular}

MS + additives. Data were taken after 3 weeks of culture. Mean frequencies \pm SE (standard error) in each column followed by same superscript letters are not significantly different according to LSD test at $\mathrm{p}<0.05$ level.

Reduction of callus growth was observed on further increase of BAP and 2,4-D concentration. After 6 weeks, it was observed that the 2,4-D and BAP combination clearly affected the callus proliferation and embryogenic callus growth in $H$. brasiliensis. From the results it was observed that the callus continued to increase up to 3 weeks after that which was declined. Browning of callus was observed after 5 weeks of culture. The best callus maintenance medium was found to be MS combined with 2,4-D $(2.0 \mathrm{mg} / \mathrm{l})$ and BAP $(2.0 \mathrm{mg} / \mathrm{l})$.

Embryogenic callus cultures were established on MS supplemented with BAP and $\mathrm{Kn}$ and 2,4-D in presence of NAA $(0.5 \mathrm{mg} / \mathrm{l})$. The most friable, fast growing and yellow callus was obtained in 2,4-D (2.0 mg/l) and $\mathrm{Kn}(2.0 \mathrm{mg} / \mathrm{l})$ after 2 weeks of culture, which differentiated into pro-embryos. The calli were routinely maintained on MS with 2, 4-D (2.0 mg/l) and $\mathrm{Kn}(2.0 \mathrm{mg} / \mathrm{l})$ by subculturing twice 
a month. The highest frequency (70\%) of embryogenic calli was induced in a medium combination of 2,4-D (2.0 mg/l) and $\mathrm{Kn}(2.0 \mathrm{mg} / \mathrm{l})$ (Table 2, Fig. 3a).

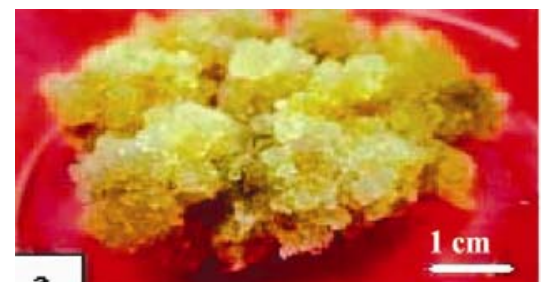

a
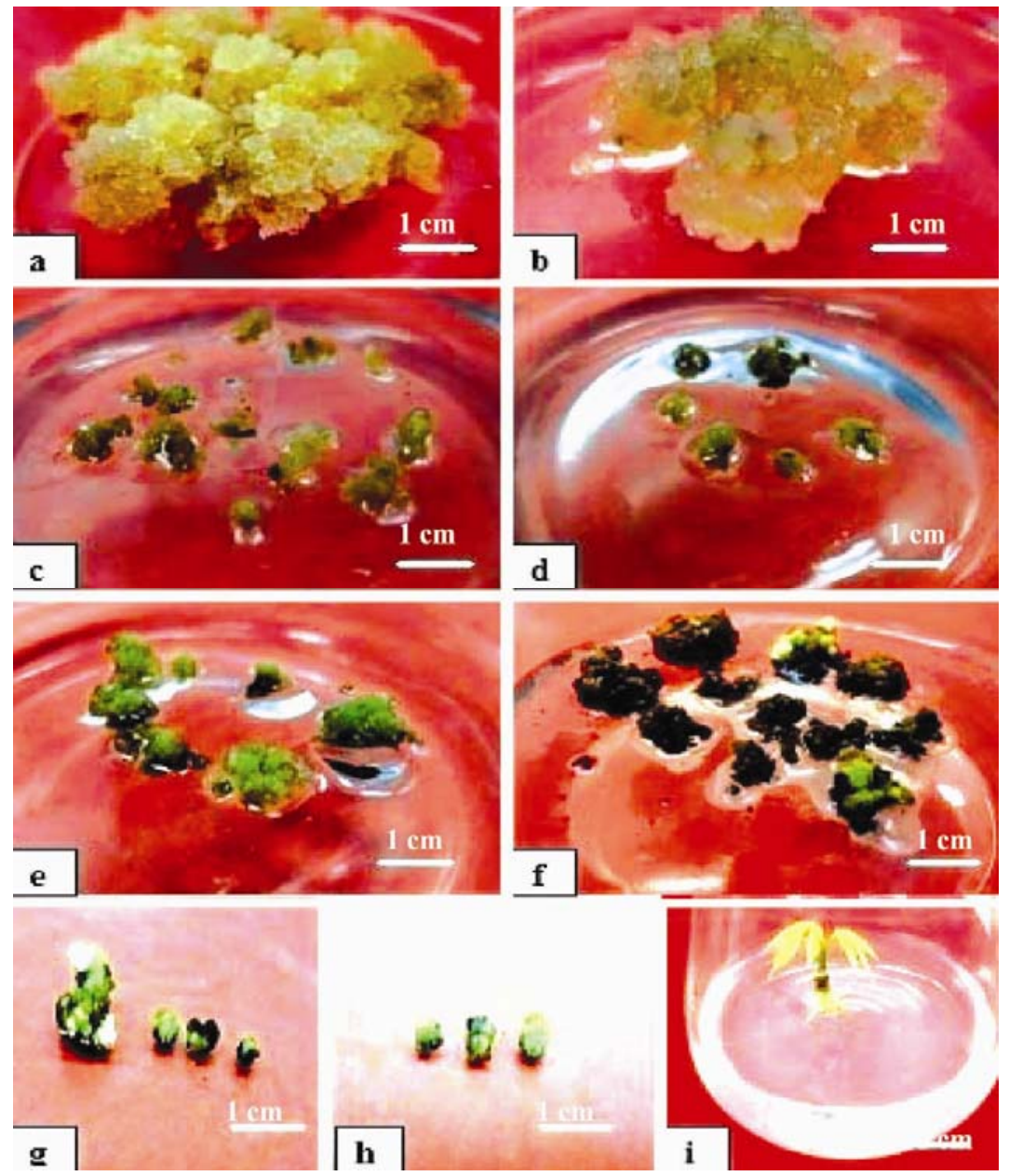

Fig. 3. Detection of somatic embryos and plantlet production from zygotic embyo derived embyogenic callus of $H$. brasiliensis. a. Yellow friable embryogenic callus, b. Embryogenic callus in embryo induction medium $\mathrm{MS}+1.0 \mathrm{mg} / \mathrm{l} \mathrm{BAP}+2.0 \mathrm{mg} / \mathrm{l} \mathrm{GA} 3+0.1 \mathrm{mg} / \mathrm{l} \mathrm{NAA}$; $\mathrm{c}$ - e. Proembryogenic message, globular / torpedo embryo initiation, f. Initiation of somatic embryos fromed the surface of the callus, g. Cluster and single embryos, h. Isolated mature embryos and i. Regenerated rooted plantlet.

Different concentrations of $\mathrm{Kn}$ had a vital role to obtain embryogenic callus line in rubber. Similarly, the role of Kn combined with auxin in embryogenesis was reported earlier in a number of plants (Ghanti et al. 2010). The inclusion of $\mathrm{Kn}$ in the medium could enhance the efficiency of calli to produce somatic embryo that could mature normally (Arya et al. 2000). The embryogenic callus 
was identified by means of anatomical studies on the basis of its yellowish colour and presence of less vacuolated and densely filled cytoplasm cells with the central nucleus. The reduce concentration of 2,4-D improved the morphogenesis of somatic embryos in Hevea. A higher concentration of 2,4-D affected negatively on callus proliferation and pro-embryo induction, due to toxic effect (Kintzios et al. 2000). The influences of exogenously applied auxins preferentially 2,4-D on somatic embryogenesis are well documented.

Table 2. Influence of 2,4-D and different concentrations of $\mathrm{Kn}$ in presence of $0.5 \mathrm{mg} / \mathrm{l}$ NAA on embryogenic callus production from zygotic embryo derived callus of Hevea.

\begin{tabular}{|c|c|c|c|c|c|}
\hline \multicolumn{3}{|c|}{$\begin{array}{l}\text { Media compositions } \\
\qquad(\mathrm{mg} / \mathrm{l})\end{array}$} & $\begin{array}{l}\text { Total no. of } \\
\text { explants }\end{array}$ & $\begin{array}{l}\text { Total no. of } \\
\text { explants } \\
\text { responded }\end{array}$ & $\begin{array}{c}\text { Mean \% of } \\
\text { embryogenic } \\
\text { callus }\end{array}$ \\
\hline \multicolumn{3}{|c|}{ MS 0 ( Control) } & 30 & $0 \pm 0^{c}$ & 0 \\
\hline $2,4-\mathrm{D}$ & NAA & $\mathrm{Kn}$ & & & \\
\hline \multirow{5}{*}{2.0} & \multirow{5}{*}{0.5} & 1.0 & 30 & $6.33 \pm 0.76^{a}$ & 63.33 \\
\hline & & 2.0 & 30 & $7.00 \pm 1.00^{\mathrm{a}}$ & 70.00 \\
\hline & & 3.0 & 30 & $5.33 \pm 0.57^{a}$ & 53.33 \\
\hline & & 4.0 & 30 & $3.00 \pm 0.50^{b}$ & 30.00 \\
\hline & & 5.0 & 30 & $1.33 \pm 0.28^{\mathrm{bc}}$ & 13.33 \\
\hline
\end{tabular}

MS + additives. Data were taken after 4 weeks of culture. Mean frequencies \pm SE (standard error) in each column followed by same superscript letters are not significantly different according to LSD test at $\mathrm{p}<0.05$ level.

The results of present study also revealed that lower concentrations of 2,4-D induced higher percentage of embryogenic callus in the dark. Wilhelm (2000) reported that, either lower concentration or devoid of plant growth regulators in culture medium favour the formation of somatic embryos. It has been also suggested that the auxins in culture medium, influences the formation of nonpolar pro-embryos affecting the further development of somatic embryos in the maturation phase (Silveira et al. 2003). Meanwhile, in this study a significant variation was noted with the changes of 2,4-D concentration with higher levels of $\mathrm{Kn}$. The percentage of embryogenesis was significantly reduced with the increasing level of $\mathrm{Kn}$ from 3.0 to $5.0 \mathrm{mg} / \mathrm{l}$. This might be due to the higher ratio of auxin and cytokinin concentration which concerned with the proliferation and development of embryo to torpedo shaped stage rather than triggering the embryogenic callus induction. Kumaria et al. (2003) reported that, a particular ratio of auxin and cytokinin might be necessary in the medium for somatic embryogenesis.

The embryonic clusters were formed on the embryo induction medium within 3 to 4 weeks which further developed into globular stage embryos. A 
lower concentration of auxin NAA had a profound influence on embryogenesis from zygotic embryo explants in rubber. Effect of $\mathrm{GA}_{3}$ and BAP with NAA on embryo induction was evaluated. The results indicated that BAP supplemented with $0.1 \mathrm{mg} / \mathrm{l}$ NAA favoured the conversion of embryogenic mass to globular/ torpedo stage embryos. The formation of globular/torpedo stage embryos per unit mass of callus varied with varying concentrations of BAP. The maximum $76.66 \%$ embryos were recorded on MS + Vit $\mathrm{B}_{5}$ medium supplemented with BAP $(1.0 \mathrm{mg} / \mathrm{l}), \mathrm{GA}_{3}(2.0 \mathrm{mg} / \mathrm{l})$ and NAA $(0.1 \mathrm{mg} / \mathrm{l})$ after 4 weeks of culture (Table 3, Fig. 3a-i).

Table 3. Effect of BAP and $\mathrm{GA}_{3}$ in combination with $0.1 \mathrm{mg} / 1 \mathrm{NAA}$ on embryo induction frequency (\%) from zygotic embryo derieved embryogenic callus.

\begin{tabular}{cccccc}
\hline NAA & $\mathrm{GA}_{3}$ & \multicolumn{4}{c}{ BAP $(\mathrm{mg} / \mathrm{l})$} \\
\cline { 3 - 6 }$(\mathrm{mg} / \mathrm{l})$ & $(\mathrm{mg} / \mathrm{l})$ & 0.0 & 1.0 & 2.0 & 3.0 \\
\hline \multirow{3}{*}{$0.1+$} & 0.5 & $10.00 \pm 0.50^{\mathrm{a}}$ & $33.33 \pm 0.76^{\mathrm{b}}$ & $43.33 \pm 0.57^{\mathrm{a}}$ & $30.00 \pm 0.50^{\mathrm{a}}$ \\
& 1.0 & $16.66 \pm 0.76^{\mathrm{a}}$ & $53.33 \pm 1.04^{\mathrm{ab}}$ & $46.66 \pm 1.25^{\mathrm{a}}$ & $33.33 \pm 0.76^{\mathrm{a}}$ \\
& 2.0 & $26.66 \pm 0.28^{\mathrm{a}}$ & $76.66 \pm 0.28^{\mathrm{a}}$ & $60.00 \pm 1.00^{\mathrm{a}}$ & $40.00 \pm 0.50^{\mathrm{a}}$ \\
& 3.0 & $13.33 \pm 1.15^{\mathrm{a}}$ & $50.00 \pm 1.00^{\mathrm{ab}}$ & $33.33 \pm 0.28^{\mathrm{a}}$ & $30.00 \pm 0.86^{\mathrm{a}}$ \\
\hline
\end{tabular}

MS + additive. Embryo induction frequency was calculated by visual counting the number of globular/torpedo stage embryos formed from approximately $500 \mathrm{mg}$ of embryogenic callus subcultured on embryo induction medium and converting into percentage. Mean frequencies \pm SE (Standard error) in each column followed by same superscript letters are not significantly different according to LSD test at $\mathrm{p}<0.05$ level.

Table 4. Effect of IBA and $\mathrm{GA}_{3}$ on embryo germination (\%).

\begin{tabular}{cccccc}
\hline $\mathrm{GA}_{3}$ & \multicolumn{5}{c}{$\mathrm{IBA}(\mathrm{mg} / \mathrm{l})$} \\
\cline { 2 - 6 }$(\mathrm{mg} / \mathrm{l})$ & 0.0 & 0.1 & 0.2 & 0.3 & 0.5 \\
\hline 0.0 & $0.00 \pm 0.00^{\mathrm{d}}$ & $10.00 \pm 0.00^{\mathrm{d}}$ & $20.00 \pm 0.50^{\mathrm{c}}$ & $13.33 \pm 0.57^{\mathrm{b}}$ & $10.00 \pm 0.50^{\mathrm{b}}$ \\
0.1 & $3.33 \pm 0.28^{\mathrm{cd}}$ & $23.33 \pm 0.28^{\mathrm{c}}$ & $43.33 \pm 1.52^{\mathrm{bc}}$ & $20.00 \pm 0.50^{\mathrm{b}}$ & $13.33 \pm 0.28^{\mathrm{b}}$ \\
0.2 & $6.66 \pm 0.28^{\mathrm{bcd}}$ & $46.66 \pm 0.28^{\mathrm{b}}$ & $53.33 \pm 1.25^{\mathrm{ab}}$ & $33.33 \pm 0.76^{\mathrm{ab}}$ & $20.00 \pm 0.50^{\mathrm{ab}}$ \\
0.3 & $20.00 \pm 0.50^{\mathrm{a}}$ & $66.66 \pm 0.76^{\mathrm{a}}$ & $80.00 \pm 1.32^{\mathrm{a}}$ & $50.00 \pm 1.32^{\mathrm{a}}$ & $30.00 \pm 0.50^{\mathrm{a}}$ \\
0.4 & $16.66 \pm 0.28^{\mathrm{ab}}$ & $33.33 \pm 0.28^{\mathrm{c}}$ & $43.33 \pm 0.28^{\mathrm{bc}}$ & $30.00 \pm 0.50^{\mathrm{ab}}$ & $20.00 \pm 0.50^{\mathrm{ab}}$ \\
0.5 & $13.33 \pm 0.28^{\mathrm{abc}}$ & $23.33 \pm 0.28^{\mathrm{c}}$ & $33.33 \pm 0.28^{\mathrm{bc}}$ & $20.00 \pm 0.00^{\mathrm{b}}$ & $10.00 \pm 0.00^{\mathrm{b}}$ \\
\hline
\end{tabular}

Medium: MS + additive. Mean \% and standard error were calculated using data taken from three replications of total 30 cultures for each treatment. The experiment repeated thrice. Mean frequencies \pm SE (Standard error) in each column followed by same superscript letters are not significantly different according to LSD test at $\mathrm{p}<0.05$ level.

It was observed that the combination of $\mathrm{BAP}$ and $\mathrm{GA}_{3}$ was required for embryo induction, maturation and germination. After 3 - 4 weeks of growth, 
embryos started to become greenish, and showed bipolar differentiation. The combination of an auxin and BAP was used to induce somatic embryos from immature and mature zygotic embryos of Quercus sp. (Wilhelm 2000).

Embryo germination was initiated by the bipolar differentiation of (root and shoot primordial) the mature embryos. The embryos developed plantlets after 4 to 5 weeks of cultureon half strength MS medium. Embryo germinated in hormone free as well as on medium fortified with phytohormone. Embryo germination was enhanced by the addition of $\mathrm{GA}_{3}$ on culture medium. The plantlets which grown in the medium containing GA3 were more vigorous than in hormone free medium. Maximum plant conversion was observed in $0.3 \mathrm{mg} / \mathrm{l}$ $\mathrm{GA}_{3}$ and $0.2 \mathrm{mg} / \mathrm{l} \mathrm{IBA}$ supplemented medium (Table 4 ).

Addition of IBA $(0.1 \mathrm{mg} / \mathrm{l}-0.5 \mathrm{mg} / \mathrm{l})$ in culture medium also favoured root elongation. About $80 \%$ of somatic embryos initiated germination and produced rooted plantlets. The plant regeneration protocol developed from zygotic embryo derived callus of H. brasiliensis (Clone RRIM 901) could be used for other rubber genotypes to produce mass scale planting materials. The regenerative embryogenic tissues established in this study could also be used to develop transgenic rubber plants with desirable genes.

\section{Acknowledgement}

Authors are thankful to the Department of Biochemistry, Universiti Putra Malaysia as well as Bangladesh Agricultural Research Council for the technical and financial support to conduct this study.

\section{References}

Arya H, Jaiswal U and Jaiswal VS (2000) Plant regeneration from protoplasts of mango (Mangifera indica L.) through somatic embryogenesis. Plant Cell Rep. 19: 622- 627.

Feher A, Pasternak TP and Dudits D (2003) Transition of somatic plant cells to an embryogenic state. Plant Cell Tiss. Org. Cult. 74: 201-228.

Ghanti SK, Sujata KG, Rao SM and Kishor PBK (2010) Direct somatic embryogenesis and plant regeneration from immature explants of chickpea. Biol. Plant 54: 121-125.

Herna'ndez I, Celestino C and Toribio M (2003a) Vegetative propagation of Quercus suber L. by somatic embryogenesis I. Factors affecting the induction in leaves from mature cork oak trees. Plant Cell Rep. 21: 759-764.

Huang G and Lin W (2003) Biochemical interaction between rootstock and scion of grafted Hevea brasiliensis. Chin. J. Trop. Crops. 24: 7-11.

Khan H, Siddique I, Anis M and Khan PR (2011) In vitro organogenesis from internode derived callus cultures of Capsicum annuum L. J. Plant Biochem. Biotechnol. 20: 84-89.

Kintzios S, Drossopoulos JB, Shortsianitis E and Peppes D (2000) Induction of somatic embryogenesis from young, fully expanded leaves of chilli pepper (Capsicum annuum 
L.): Effect of leaf position and explants pre-treatment with high cytokinin concentrations. Sci. Hort. 85: 137-144.

Kumaria R, Sunnichan VG, Das DK, Gupta SK, Reddy VS, Bhatnagar RK and Leelavathi S (2003) High frequency somatic embryo production and maturation into normal plants in cotton (Gossypium hirsutum) through metabolic stress. Plant Cell Rep. 19: 1057-1063.

Silveira V, Floh EIS, Handro W and Guerra (2003) Effect of plant growth regulators on the cellular growth and levels of intracellular protein, starch and polyamines in embryogenic suspension culture of Pinustaeda. Plant Cell Tiss. Org. Cult. 76: 53-60.

Sobhana P, Gopalakrishnan J, Jacob J and Sethuraj MR (2001) Physiological and biochemical aspects of stock-scion interaction in Hevea brasiliensis. Indian J. Nat. Rubber Res. 14: 131-136.

Sushamakumari S, Sobha S, Rekha K, Jayashree R and Asokan MP (2000b) Influence of growth regulators and sucrose on somatic embryogenesis and plant regeneration from immature inflorescence of Hevea brasiliensis. Indian J. Nat. Rubber Res. 13: 19-29.

Wilhelm E (2000) Somatic embryogenesis in oak (Quercus spp.). In Vitro Cell Dev. Biol. Plant 36: 349-357. 